\title{
Integrated Use of Satellite Altimetry in the Investigation of the Meteorological, Hydrological, and Hydrodynamic Regime of the Caspian Sea
}

\author{
Sergey A. Lebedev ${ }^{1,2, *}$ and Andrey G. Kostianoy ${ }^{3}$ \\ ${ }^{1}$ Geophysical Center, Russian Academy of Sciences, Moscow, 119296, Russia \\ ${ }^{2}$ State Oceanographic Institute, Moscow, Russia \\ ${ }^{3}$ P.P. Shirshov Institute of Oceanology, Russian Academy of Sciences, Moscow, Russia
}

Received 15 November 2006, accepted 8 June 2007

\begin{abstract}
Oscillations in the Caspian Sea level represent the result of mutually related hydrometeorological processes, which proceed not only in the sea catchment area but also far beyond it. The change in the tendency of mean sea level variations that occurred in the mid 1970s, when a long-term level fall was replaced by a rapid and significant rise, represents an important indicator of the changes in the natural regime of the Caspian Sea. Therefore, sea level monitoring and long-term forecast of sea level changes represent an extremely important task. The aim of this publication is to show the results of the application of satellite altimetry methods to the investigation of seasonal and interannual variability of the sea level, wind speed and wave height in different parts of the Caspian Sea and Kara-Bogaz-Gol Bay, and the Volga River level. The work is based on the 1992 - 2006 TOPEX/Poseidon and Jason-1 datasets.
\end{abstract}

Key words: Sea level, Wind speed, Wave height, Caspian Sea, Kara-Bogaz-Gol Bay, Satellite altimetry, TOPEX/Poseidon, Jason-1

Citation: Lebedev, S. A., and A. G. Kostianoy, 2008: Integrated use of satellite altimetry in the investigation of the meteorological, hydrological, and hydrodynamic regime of the Caspian Sea. Terr. Atmos. Ocean. Sci., 19, 71-82, doi: 10.3319/TAO.2008.19.1-2.71(SA)

\section{INTRODUCTION}

The Caspian Sea is the world's largest isolated water reservoir, with only isolation being its significant dissimilarity from the open seas. Other features of the Caspian Sea including its size, depth, chemical properties, peculiarities of thermohaline structure, and water circulation allow it to be classified as a deep inland sea. At the present time its level is at $-27 \mathrm{~m}$ (with respect to the Baltic altitude system) measured against the World Sea Level. The sea occupies an area of $392600 \mathrm{~km}^{2}$, with mean and maximum depths being 208 and 1025 m, respectively (Fig. 1). The Caspian's longitudinal extent is three times larger than its latitudinal one (1000 vs. $200-400 \mathrm{~km})$, resulting in great variability of climatic conditions over the sea. The isolation of the Caspian Sea from the ocean and its inland position dictate the significance of its outer thermohydrodynamic factors, specifically, heat and water fluxes through the sea surface, and

\footnotetext{
* Corresponding author

E-mail:lebedev@wdcb.ru
}

river discharge over sea level variability, formation of its 3D thermohaline structure, and water circulation (Kosarev and Yablonskaya 1994).

Over the past half-century, there was a regression of the Caspian Sea level (CSL) until 1977 when the sea level lowered to $-29 \mathrm{~m}$ (Fig. 2). It is obvious that man's impact led to a more than $1.5 \mathrm{~m}$ regression of the CSL caused by the creation of cascade reservoirs in the Volga and Kama Rivers. This drop is considered to be the deepest for the last 400 - 500 years (Kosarev and Yablonskaya 1994). In 1978 the water level started to rise rapidly, and now it has stabilized at the $-27 \mathrm{~m}$ level. There has been increasing concern over CSL fluctuations.

Perennial level variations of the Caspian Sea and components of its water balance (WB) are investigated using different approaches; however, the physical mechanism generating the long-term directed CSL changes is not understood yet. Researches of recent years (Golitsyn and Panin 1989; Panin et al. 1991; Rodionov 1994; Golitsyn 1995; 
Voropayev 1997; Mikhailov 1998; The Caspian Sea Environment 2005) have focused on the climatic nature of modern level variations, and also the water and heat balance of the Caspian Sea.

The Caspian Sea level is governed by river discharge, mainly the Volga River, and the sum of precipitation minus evaporation over the Caspian Sea. Latest investigations

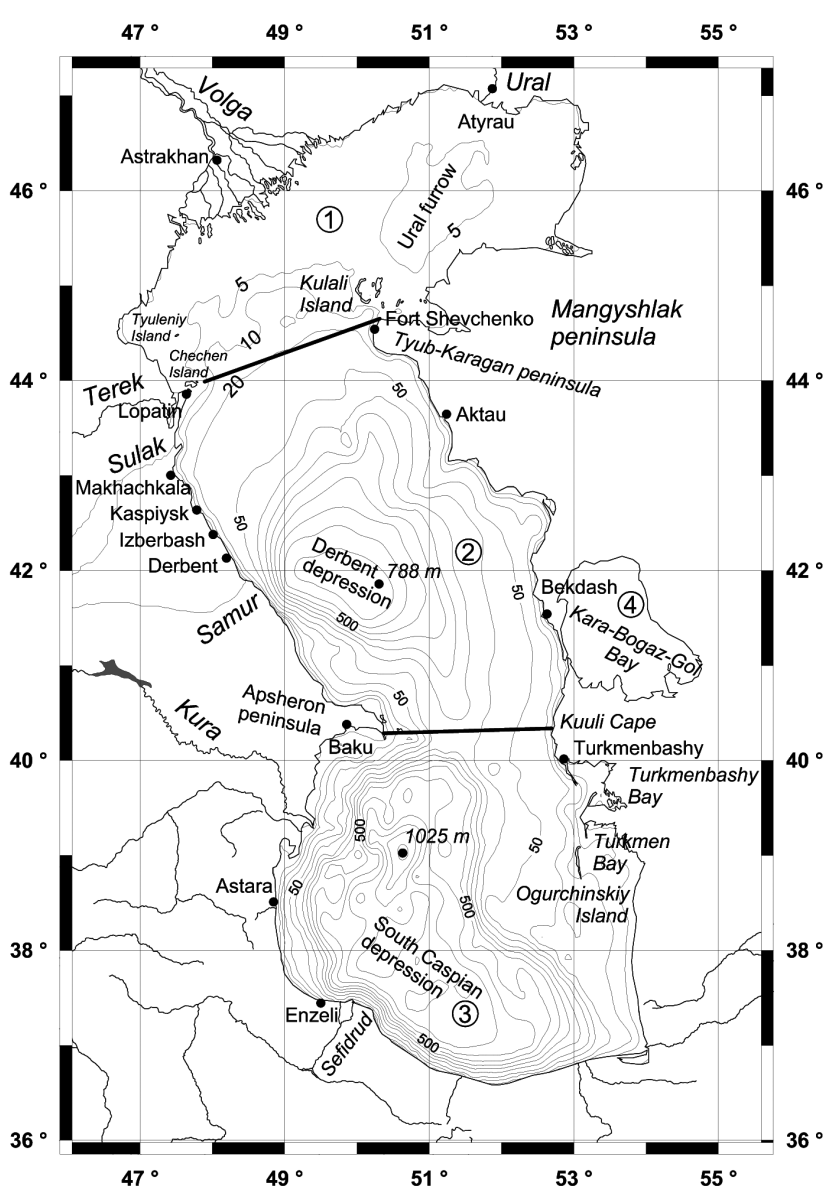

Fig. 1 The Caspian Sea. Main parts of the Caspian Sea:

1: the North Caspian, 2: the Middle Caspian, 3: the South Caspian, 4: the Kara-Bogaz-Gol Bay. Isobaths are shown in meters.

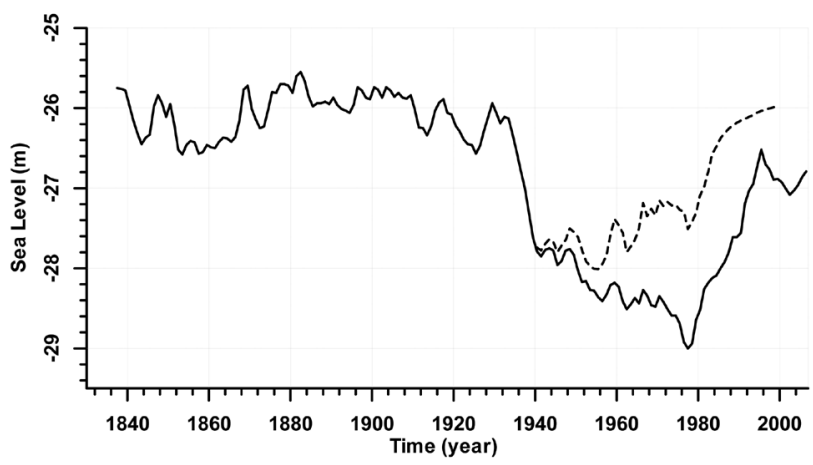

Fig. 2. Interannual variations of the Caspian Sea level measured by SLG since 1837 till 2006 (solid line) and reconstructed sea level (dotted line) without man's impact on the VDV by data of Voropayev (1997). show how the impacts of El Niño/Southern Oscillation (ENSO), the North-Atlantic Oscillation and Southern Oscillation Index and global warming impact Volga River discharge (VRD) and consequently influence indirectly CSL variability (Arpe et al. 2000). For example, more warm ENSO events (El Niño) has led to enhanced Volga river discharge and an increase in the CSL, as well as increased land and sea surface temperatures (Ginzburg et al. 2005), chlorophyll concentration (Nezlin 2005), wind speed and the rate of evaporation from the Caspian Sea surface (Panin et al. 2003).

Unfortunately evaporation on the Caspian Sea surface, which plays a key role in WB and CLS variability, is difficult to observe. Information on many parameters pertaining to atmospheric and sea surface conditions (air and sea temperature, air humidity, wind speed, wave heights) are necessary for calculating evaporation. In this case, remote sensing data and results of atmospheric simulation are beneficial in investigating WB and CSL variability. Since the early 1990s regular monitoring of Caspian Sea surface temperature, sea levels, chlorophyll concentration, mesoscale dynamics, wind and waves, and some meteo parameters have been made available based on satellite IR and VIS data (AVHRR NOAA, MODIS), altimetry data, scatterometry data and NCEP/NCAR Reanalysis data.

Thus satellite altimetry (SA) on one hand allows for analysis of CSL variability in offshore water, while on the other it enables us to define some of the parameters necessary for calculating an evaporation value and joint investigation of seasonal and interannual variability of WB and CSL including VRD.

Traditionally, sea level variations, which are conditional upon different factors, were investigated based on sea level gauge (SLG) data. But these data usually give information on sea level change only close to the coastline, which has a significant impact on measured data. Also, according to recent GPS measurements, some SLG data, for example, from the Barents, Baltic and Caspian seas (Scherneck et al. 2001; Lebedev and Kostianoy 2005), have positive vertical lift, which is conditional on the motion of the Earth's crust. It also introduces considerable error into interannual variability of sea levels. Moreover, regular sea (lake) level measurements are practically absent for some regions in Africa and Central Asia (Kostianoy et al. 2004; Hwang et al. 2005; Cretaux et al. 2006).

These problems can be solved by use of SA. It measures sea surface height (SSH) relative to a reference ellipsoid (or the gravity center) that allows for the elimination of vertical lift in the Earth's crust from interannual level variation. Spatial and temporal resolution of SA data allows for investigation of seasonal and interannual variability of ocean, sea, lake and river levels (Morris and Gill 1994a, b; Birkett 1995; Larnicol et al. 1995; Cazenave et al. 1997; Fenoglio-Marc 2001; Nerem and Mitchum 2001; Mercier et 
al. 2002; Lebedev et al. 2003; Kostianoy et al. 2004, Lebedev and Kostianoy 2005).

The experience of these researchers has allowed for the creation of some projects such as the: investigation of variability of closed seas, lakes, reservoirs and river levels with SA data; and Hydrology from Space (Hydroweb), Global Reservoirs and Lake Monitor (GRLM) and River and Lake Hydrology (RLH), which are all now Internet resources.

Cazenave et al. (1997) and Vasiliev et al. (2002) have shown that SA data can be successfully used for the investigation of CSL variability when traditional SLG measurements are deficient. The spatial location of the TOPEX/ Poseidon (T/P) and Jason-1 (J1) ground tracks at the sea surface makes it possible to investigate different features of hydrological and hydrodynamic regimes of the northern, middle and southern regions of the Caspian Sea, as well as the Kara-Bogaz-Gol Bay (Fig. 3).

In this paper, we examine the how the application of SA data is able to assist in monitoring sea level, wind speed, wave height and surface dynamic variations in the Caspian Sea, as well as the water level of the Volga River. Results of verification of calculations using SA data with in situ mea-



Fig. 3. Map of the Caspian Sea, ground tracks and crossover points of the T/P and J1. SLG are shown as follows:

1: Makhachkala, 2: Fort Shevchenko, 3: Zhiloy Island, 4: Kara-BogazGol, 5: Turkmenbashi, 6: Baku, 7: Neftyanye Kamni, 8: Kuuli Mayak. surements from SLG and meteorological stations are also shown.

\section{DATA}

To analyze Caspian Sea level variations, measurements from both the T/P and $\mathrm{J} 1$ satellites were used for the following reasons. The precision of SSH measurements by T/P and $\mathrm{J} 1$ to the relative reference ellipsoid is $1.7 \mathrm{~cm}$ (Fu and Pihos 1994), which is higher than other altimetry missions (Chelton et al. 2001). At the same time, accuracy of sea level measurements is at $\sim 4 \mathrm{~cm}$ (Birkett 1995; Nerem and Mitchum 2001) that allows adequate accuracy for studies to be conducted. The position of $\mathrm{T} / \mathrm{P}$ and $\mathrm{J} 1$ ground tracks (Fig. 3) is optimal for analysis of sea level variations in the Caspian Sea. The orbital repeat period ( $\sim 10$ days) enables analysis of interannual and seasonal variability of the sea level. The T/P data represent the longest time-series of satellite altimetric measurements (September 1992 to August 2002 or from 1 to 365 cycles) with the possibility of the data being extended by $\mathrm{J} 1$ data along the same tracks (August 2002 to the present).

We have analyzed T/P and J1 data since September 1992 until December 2006. SA data from T/P and J1 were obtained from the NASA Goddard Space Flight Center (GSFC) Ocean Altimeter Pathfinder Project (Koblinsky et al. 1999a, b). Besides which, T/P merged geophysical data records (MGDR) were obtained from the NASA Physical Oceanography Distributed Active Archive Center (PODAAC) at the Jet Propulsion Laboratory (JPL) of California Institute of Technology (Benada 1997). The J1 Interim Geophysical Data Record (IGDR) and Geophysical Data Record (GDR) were obtained from AVISO (Archivage, Validation et Interprétation des données des Satellites Océanographiques) and PODAAC (Picot et al. 2006). Information and software of the Integrated Satellite Altimetry Data Base (ISADB) developed in the Geophysical Center of Russian Academy of Sciences (Medvedev et al. 1997; Lebedev and Kostianoy 2005) have been used for data processing and analysis.

Also we used the next mean sea surface (MSS) model: CSR95, OSU95, GSFC00, CLS_SHOM98, and CLS01 (Rapp 1998; Hernandez and Schaeffer 2000; Wang 2000; Tapley and Kim 2001) - for acceptability appraisal of these MSS for investigation of the hydrologic and hydrodynamic regime of the Caspian Sea. The received results were compared to data of the Hydroweb (http://www.legos.obs-mip. fr/soa/hydrologie/hydroweb/) and GRLM (http://www.pecad.fas.usda.gov/cropexplorer/global reservoir/) and verified according to meteostation and SLG data, collected around the Caspian Sea coast. Additional meteorological NCEP/ NCAR Reanalysis data (Kistler et al. 2001) was used also for control of tropospheric corrections, which are necessary for processing SA data. 


\section{METHODOLOGY}

\subsection{Sea Surface Height or Sea Level}

Data processing methods and analysis as well as obtained results on the Caspian Sea level, wind speed, and wave height variations were described in detail in the book by Lebedev and Kostianoy (2005). We would like to give a brief account of its features.

Methodologies for investigation of CSL variation realized as a web-resource exist at the present time. This resource is based on analysis of sea level anomalies (SLA), which are calculated as deviations in SSH with respect to MSS while taking into account all necessary corrections. Thus the CSL temporal variability of the Hydroweb has been constructed according to satellites TP, J1, ERS, GFO, and Envisat data by averaging SLA along each track and for each satellite. GRLM data were based on this methodology only for one track (092) and for two satellites, TP and J1 data.

In our opinion, this approach contains a number of shortcomings (shown below) as the task of construction of MSS for the Caspian Sea is sufficiently obscure. A more complete realization of CSL variability requires consideration of the peculiarities of the Caspian Sea hydrological and hydrodynamical regime (storm surges, sea ice). An area of concern is the region of the Northern Caspian Sea, where these peculiarities can be saliently observed.

Firstly, it is storm surges, which depend on wind field and local physico-geographical conditions. The surges manifest most apparently in the sea's coastal zones, bays and bights. The highest onsets are characteristic of the shallowwater North Caspian, where, in extreme cases, surges can reach heights of 3 - $4 \mathrm{~m}$. In the middle and southern parts of the sea, surges are smaller though still significant. According to long-term observation data, the greatest heights of onsets are $50-70 \mathrm{~cm}$, while offsets can reach values of $30-100 \mathrm{~cm}$; thus, the range in sea level variations is $100-150 \mathrm{~cm}(\mathrm{Ko}-$ sarev 2005).

Secondly, there is the issue of sea ice. In moderate winters, ice formation begins in the middle of November in the shallow-water northeastern regions of the sea; by the end of this month, ice has developed along the entire northern coast of the sea. By the beginning of January, the entire area of the North Caspian is covered with ice. In the Middle Caspian, ice appears in December and in January it appears in the region of Makhachkala. In warm winters, ice formation in near-shore zones begins 10 - 20 days later than in moderate winters; in the open sea, it can be delayed for more than a month. In severe winters, ice formation in the North Caspian proceeds 20 - 30 days earlier than usual. On the eastern coast of the Middle Caspian, ice formation is possible as early as at the end of October - November, while on its western coast it starts at the end of November - beginning of December. Ice decay starts in March: open areas and shallow regions in the northwestern part become ice-free in
mid-March and in the region near the Volga delta by late March. In the beginning of April, the ice disappears in the northeastern part; the last ice resides over the Ural furrow. On average, the duration of the ice period is 120 - 140 days in the eastern part of the Northern Caspian and 80 - 90 days or less in the western part (Kouraev et al. 2004; Kosarev 2005).

Thirdly, there is the issue of Caspian Sea WB peculiarities. The most important of these are the VRD (more $80 \%$ ), evaporation from the sea surface and the dynamics between the Caspian Sea and Kara-Bogaz-Gol Bay. Thus for the period of time when SA measurements were conducted from 1985 until 2006 water discharge in the Volgograd power station oscillated from $5609.25 \mathrm{~m}^{3} \mathrm{c}^{-1}$ (2006) to 1136983 $\mathrm{m}^{3} \mathrm{c}^{-1}$ (1996) and was on average $8450.33 \mathrm{~m}^{3} \mathrm{c}^{-1}$ (Kosarev 2005; Lebedev and Kostianoy 2005). In June 1992, the dam between the Caspian Sea and the Kara-Bogaz-Gol Bay was destroyed and the natural seawater runoff to the bay resumed. Up to the middle of 1996, the bay was rapidly filled with Caspian water (Lebedev and Kostianoy 2005; The Caspian Sea Environment 2005).

Fourthly, there is the special issue of flood surge passage over the Caspian Sea area, seiche and baric waves (Kosarev and Yablonskaya 1994; The Caspian Sea Environment 2005).

Thus, calculation of SLA relative to MSS for analysis of CSL synoptics, seasonal or interannual variability will certainly contain a MSS error that on average can range from 27 to $38 \mathrm{~cm}$ (Lebedev and Kostianoy 2005); this is comparable to CSL seasonal variability. For this reason we suggest investigating $\mathrm{SSH}$ variation at different crossover points of ascending and descending passes (Fig. 3), located at distances of more than $20 \mathrm{~km}$ from the coastline with consideration given to necessary corrections. Dry tropospheric correction and inverse barometer correction were recalculated on NCEP/NCAR Reanalysis data. In the mean time of $\mathrm{T} / \mathrm{P}$ and $\mathrm{J} 1$ tandem work analysis of these data has shown, that for unification of SA data it was necessary to consider constant correction for $\mathrm{J} 1$ data equal $-0.26 \mathrm{~m}$. The obtained results were united and applied to the Baltic altitude system.

\section{WIND SPEED AND WAVE HEIGHT}

Wind speed (WS) and significant wave height (SWH) measured on $\mathrm{Ku}(13.6 \mathrm{GHz})$ and $\mathrm{C}(5.3 \mathrm{GHz})$ band is all from the SA T/P and J1 data base (Benada 1997; Picot et al. 2006). Accuracy of these measurements, WS and SWH, amounts to $1.5 \mathrm{~m} \mathrm{c}^{-1}$ and $0.4-10 \%$, respectively (Benada 1997; Picot et al. 2006). This WS and SWH data was used for investigation of seasonal and temporal variation of these parameters on the Caspian Sea. Usually for analyses we take $\mathrm{SWH}$ data measured on $\mathrm{Ku}$ band $\left(\mathrm{SWH}_{\mathrm{Ku}}\right)$. If $\mathrm{SWH}_{\mathrm{Ku}}$ data is absent, then in this case $\mathrm{SWH}$ data measured on $\mathrm{C}$ band 
$\left(\mathrm{SWH}_{\mathrm{C}}\right)$ is utilized. When both measurements were available the different between them was explored. Data unrelated to the following criterion: $\left|\mathrm{SWH}_{\mathrm{Ku}}-\mathrm{SWH}_{\mathrm{C}}\right| \leq 2 \mathrm{~m}$ were not used in our investigation. According to the recommendation of experts (Benada 1997; Picot et al. 2006), values of SWH exceeding $11 \mathrm{~m}$ were excluded from calculations.

\section{THE CASPIAN SEA}

\subsection{Sea Surface Height or Sea Level}

We took two points in the Northern Caspian (057 - 092 and 133 - 244), two points in the Middle Caspian (133 - 092 and 209 - 092), and three points in the Southern Caspian (209 - 016, 031 - 092, and 031 - 016). For example, SSH variability at point 133 - 092 is shown in Fig. 4 and the integrated CSL variability in Fig. 5.

Between October 1992 and March 1995 CSL was still rising at a rate of $+20.4 \mathrm{~cm} \mathrm{yr}^{-1}$. In August 1995, the sea level started to drop abruptly and a negative trend was observed until winter 2001/2002, when a local minimum $(-27.3 \mathrm{~m})$ was reached (Fig. 5). From November 1995 to September 1996 the rate of CSL drop was $23.1 \mathrm{~cm} \mathrm{yr}^{-1}$; later

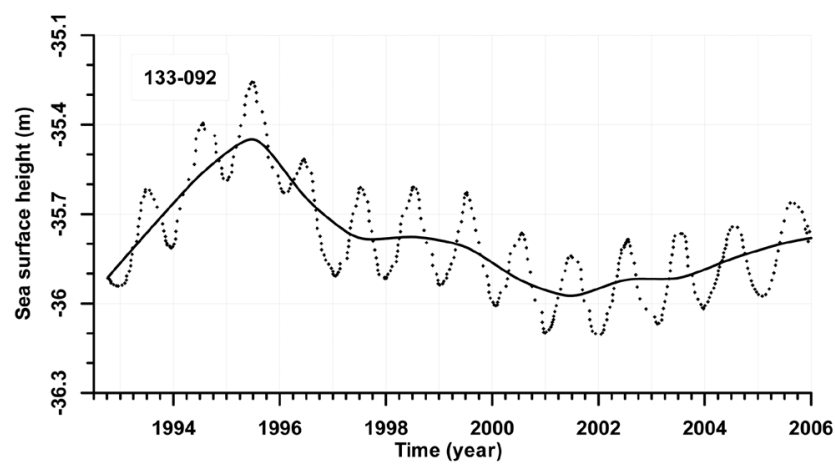

Fig. 4. The CSL variability ( $\mathrm{SSH}, \mathrm{m}$ ) at crossover point 133 - 092 from September 1992 until January 2006 on the basis of SA data of the $\mathrm{T} / \mathrm{P}$ and $\mathrm{J} 1$.

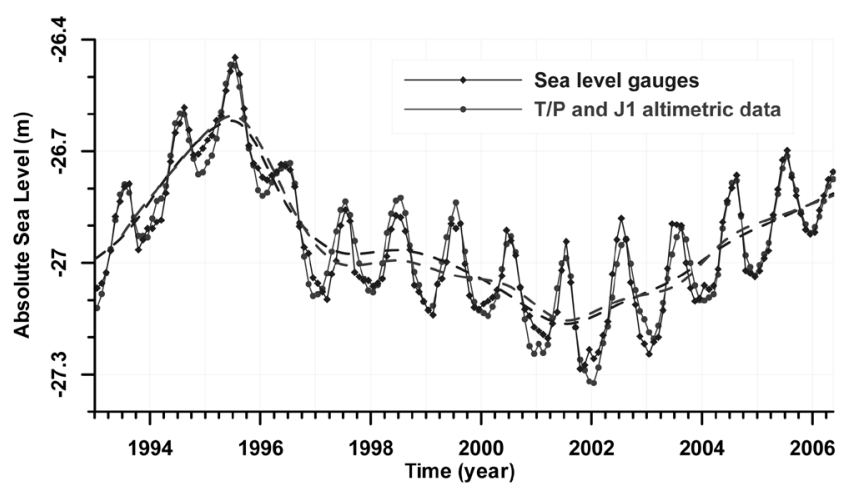

Fig. 5. The CSL variability (m) from January 1993 until May 2006 on the basis of SLG and SA data of the T/P and J1. Dashed lines - interannual variability, solid lines with markers - seasonal variability. it decreased to $-5.3 \mathrm{~cm} \mathrm{yr}^{-1}$ in October 1996 - June 1998 and to $-9.1 \mathrm{~cm} \mathrm{yr}^{-1}$ in December 1998 - April 2001. From January 2002 until December 2005 the CSL rose at a mean rate of $+7.5 \mathrm{~cm} \mathrm{yr}^{-1}$. At the present time the CSL rate is decreasing at $+4.5 \mathrm{~cm} \mathrm{yr}^{-1} .2006 \mathrm{VRD}$ data was the last comparative data acquired for the period 1992 to 2006.

According to our calculations between October 1992 and March 1995 the CLS rate $\left(+20.4 \mathrm{~cm} \mathrm{yr}^{-1}\right)$ exceeded the value of $+18.9 \mathrm{~cm} \mathrm{yr}^{-1}$ presented in the article (Casenave et al. 1997). Deviation of CSL rate values was caused by the fact that the T/P MGDR data bases have the dry correction error. NCEP/NCAR Reanalysis data have shown that atmospheric pressure, which was the basis of the dry correction calculation, decreased on average from 1042 to 1015 hPa from winter 1992 to summer 1995 (Lebedev and Kostianoy 2005). This fact has no physical explanation; probably a calculation error occurred in the T/P GDR data base's formation. It has accordingly brought about discrepancy in the SSH and the CSL rise rate decreased; the maximum of which was observed in summer 1995.

We have to note that the Northern, Middle and Southern Caspian have slightly different temporal behavior in their sea levels as well as their rate of change (Lebedev and Kostianoy 2005). Comparison of SSH variations in 7 crossover points with data of 8 SLG has shown that a maximal value of the correlation coefficient 0.967 was observed between a station in Baku and crossover point 209 - 092 (Fig. 3). For sea level time variability of the whole sea, which is traditionally calculated based on SLGs in Makhachkala, Baku, Fort Shevchenko and Krasnovodsk (nowadays Turkmenbashi), the correlation coefficient for all crossover points is higher than 0.94 .

For accuracy estimation of the offered methodology, Hydroweb and GRLM data have been applied. Hydroweb and GRLM data correlate among themselves with a coefficient 0.955 . Data about CSL calculated by the offered methodology correlate with these data as follows: ISADB and Hydroweb at 0.969, ISADB and GRLM at 0.959. These numbers are well coordinated with results calculated for temporal variation in the CSL by SA and SLG data.

According to calculations on the Northern Caspian Sea seasonal CSL maximum is observed in June at crossover point 057 - 092, which is the closest point to the Volga River delta. On the Middle Caspian Sea the seasonal CSL maximum is obtained in July and a minimum in December. The amplitude seasonal CSL maximum on the Southern Caspian Sea comes in August (Fig. 6). On average, the seasonal amplitude of sea level variability is about $25-30 \mathrm{~cm}$ for all parts of the Caspian Sea.

\section{GCRAS05 MEAN SEA SURFACE MODEL}

Existing MSS models essentially differ according to the used information or temporal averaging interval (Fig. 7). 
From March 1985 until 1996 the sea level increased 1.5 meters and then (after peak in June 1996) fell to more than $0.5 \mathrm{~m}$ (April 2000). At the same time, from December 1988 until April 1992 satellite measurements of the SSH were absent from MSS models.

Analysis of MSS models shows that the GSFC00 model is optimal for the Caspian Sea. It is to the maximum approached to geoid height $(\mathrm{GH})$, calculated on model EGM96 with decomposition to 360 degrees. In this case the root-mean-square (RMS) deviation of a difference between $\mathrm{SSH}$ and GH is minimal at $17 \mathrm{~cm}$, and the correlation coefficient is maximal at 0.999 (Lebedev and Kostianoy 2005). A possible explanation for this is that this model uses the longest time series of T/P data available.

We have already mentioned that calculation of SLA relative to any MSS model for analysis of CSL synoptic or seasonal variability must definitely contain errors. On the average they can range from 27 to $38 \mathrm{~cm}$ and that this is congruent with CSL seasonal amplitude fluctuations.

It would be possible to avoid these errors if a new MSS model could be constructed according to a hydrological and hydrodynamic regime of the Caspian Sea.

We would like to illustrate this fact with the following data. We consider SSH variation along 092 tracks for the time interval 1993 - 2006 after filtration of the CSL synoptic and seasonal variability. It is apparent (Fig. 8), that a SSH maximum for the period from September 1992 to June 2004 at latitude $43.5^{\circ} \mathrm{N}$ corresponds to the CSL maximum observable in the summer of 1995.

Between $43^{\circ} \mathrm{N}$ and the boundary of the Northern and Middle Caspian Sea strong modification of SHH gradient along a 092 track is observed in spatial position isoline at $-35.5 \mathrm{~m}$ (Fig. 8a). This SSH response is explicable due to this area depth changing from 10 to $50 \mathrm{~m}$. Gravity anomaly (GA) increases from 11.4 to $22.6 \mathrm{mGal}$ and also the gravity anomaly gradient (GAG) along the track has maximum $0.27 \mathrm{mGal} \mathrm{km}^{-1}$ (Fig. 8b). At latitude $39.8^{\circ} \mathrm{N} \mathrm{SSH}$ minimum vanish from 1994 to 1997, and then reappears. It is readily visible in the spatial position isoline at $-46 \mathrm{~m}$ (Fig. 8a). The position of this minimum correlates well to about a GA minimum of $-98.8 \mathrm{mGal}$ (Fig. $8 \mathrm{~b}$ ).

The SSH gradient over time behaves differently. We would like to illustrate this with calculations of the annual SSH gradient over time along 092 tracks (Fig. 8c). These results confirm our assumption for the necessity to create a new MSS model for the Caspian Sea.

The GCRAS05 MSS model of the Caspian Sea was calculated according to the following scheme. At first from the T/P and J1 SA data, the SSH synoptic and seasonal variations for all passes of each repeat cycle were eliminated. In last phase, the GCRAS05 MSS Model (Lebedev and Kostianoy 2005) was constructed as a function of latitude, longitude, and time with consideration for climatic dynamic topography (Fig. 8a).
The climatic dynamic topography (DT) (or hydrodynamic level) was calculated on the base of a three-dimensional baroclinic model with a free surface, average monthly fields of temperature and salinity, climatic VRD, irregular evaporation from the sea surface, and atmospheric fields from the regional model over the period from 1948 to 2006 (Fig. 9). This model was developed in the Laboratory of Sea Applied Research of the Hydrometeorological Research Center (HRC) of the Russian Federation (Verbitskaya et al. 2003; Popov 2004).

For example, analysis of the time-space variability of sea levels was done as a difference between pairs of two sequential years. It was shown that the maximum sea level rise of $22.8 \mathrm{~cm} \mathrm{yr}^{-1}$ was observed in the central part of the Middle Caspian in 1993 - 1995. In the same area a sea level rate decrease of -28 to $-8 \mathrm{~cm} \mathrm{yr}^{-1}$ was traced from 1997 to 1999 (Lebedev and Kostianoy 2005).

\section{DYNAMIC TOPOGRAPHY}

Dynamic topography was constructed on the basis of the superposition of the SLA (calculated relative to the



Fig. 6. Seasonal variability of SSH anomaly $(\mathrm{cm})$ in the Northern (at crossover point 057 - 092), the Middle (133 - 092 and 209 - 092) and the Southern Caspian (031 - 092) for September 1992 - January 2006. All crossover points are distributed along 092 track.

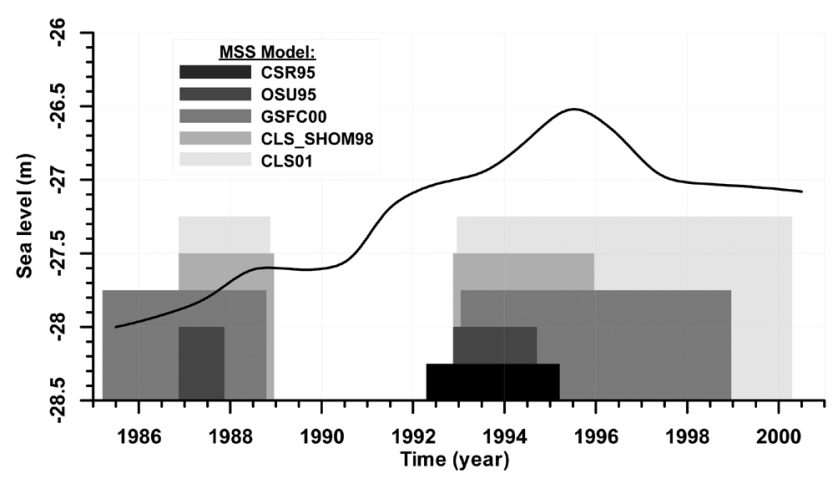

Fig. 7. Comparison of temporal intervals of average SA data for principal MSS model and the CSL variability from January 1985 to December 2001. 
(a)

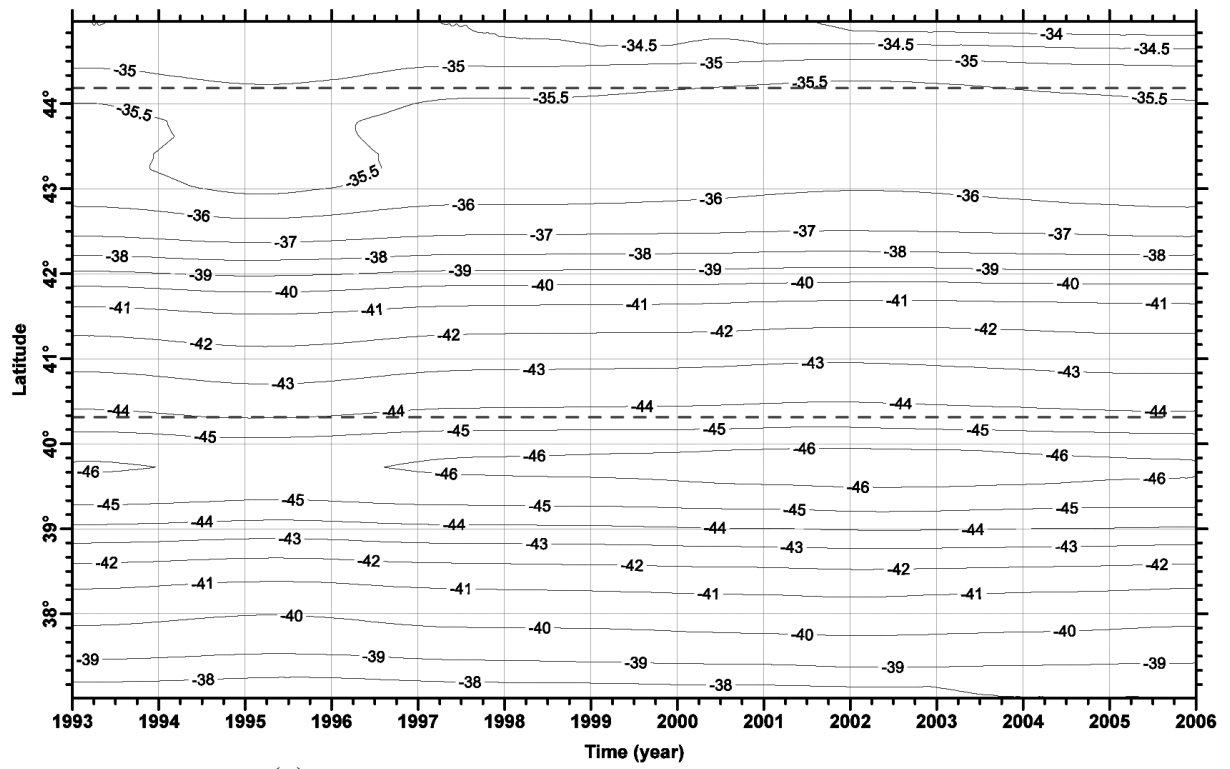

(b) Ga Gradient (mGal/km)



(c)

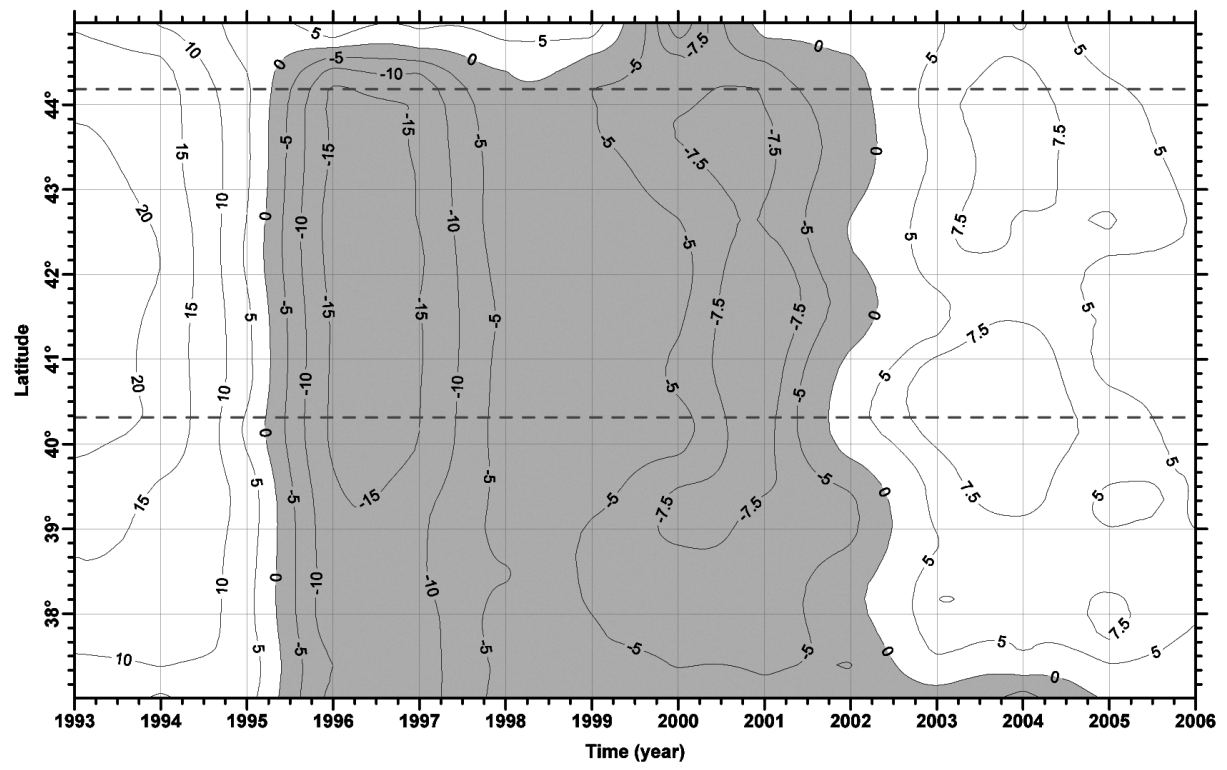

Fig. 8. Time variability: (a) of SSH without seasonal and synoptic variability or part of the GCRAS05 MSS Model (m), (b) annual MSS gradient $\left(\mathrm{cm} \mathrm{yr}^{-1}\right)$ along the descending 092 track from September 1992 to December 2006 on the basis of SA data of the T/P and J1, (c) Variability of GA (firm line) and GA gradient (dashed line) calculated by EGM96 model, decomposing to 360 degrees. Gray dashed lines show borders of the Northern-Middle and the Middle-Southern parts of the Caspian Sea.

GSRAS05 MSS model) distribution over the climatic dynamic topography, which was calculated by the HRC model (Verbitskaya et al. 2003; Popov 2004) (Fig. 10). The sea level anomalies were calculated relative to the GCRAS05 MSS Model, because the Caspian Sea level has strong interannual variability (1992 to 2005 of about $60 \mathrm{~cm}$ ).

Analysis of seasonal DT shows existence of a gyre in the Middle Caspian, which changes its direction of rotation from a cyclonic one in winter months to an anticyclonic one in summer months (Fig. 11). This transformation seems to be conditioned by seasonal variability of the VRD and wind conditions over the Caspian Sea.

Dynamics of the Southern Caspian Sea have a pronounced vortical nature (Fig. 10); wind variability is a cause of this phenomenon.

\subsection{Wind Speed and Wave Height}

The wind regime of the Caspian Sea is defined by three principal factors: regional atmospheric activity, topography 
of the coasts (orography) and local circulation induced by the thermal increments between the land and sea.

Verification of WS calculated on SA data was done during scientific research experiment AQUASONE (July 24 - August 9, 2006) conducted by the P.P. Shirshov Institute of Oceanology. Information from coastal meteorological stations (Astrakhan, Kochubey, Makhachkala/Uitash, FortShevchenko) was compared to SA data close to a coastal line. The area of expedition was crossed by three $\mathrm{J} 1$ tracks: 057, 092, and 133. From 20 July to 15 August 2006 it reached three extract repeat cycle $(167,168$, and 169).

Comparison of WS-data meteorological stations and results of calculations of SA data have shown that in-situ data and remote sensing measurements coincide within the limits of accuracy for SA methods. The coefficient of correlation between these types of data was 0.819 .

Interannual and seasonal variability of wind speed and wave height have been investigated on the basis of the same datasets (Lebedev and Kostianoy 2005). Some of the results are shown in Figs. 11 - 12. For example, it was shown that in general wind speed is 1.5 times higher in winter than in summer with a maximum in the Middle Caspian (Fig. 12). Seasonal variability of significant wave height shows that in general in the Middle Caspian wave heights are two times higher in winter than in summer and 1.5 times higher in the Southern Caspian.

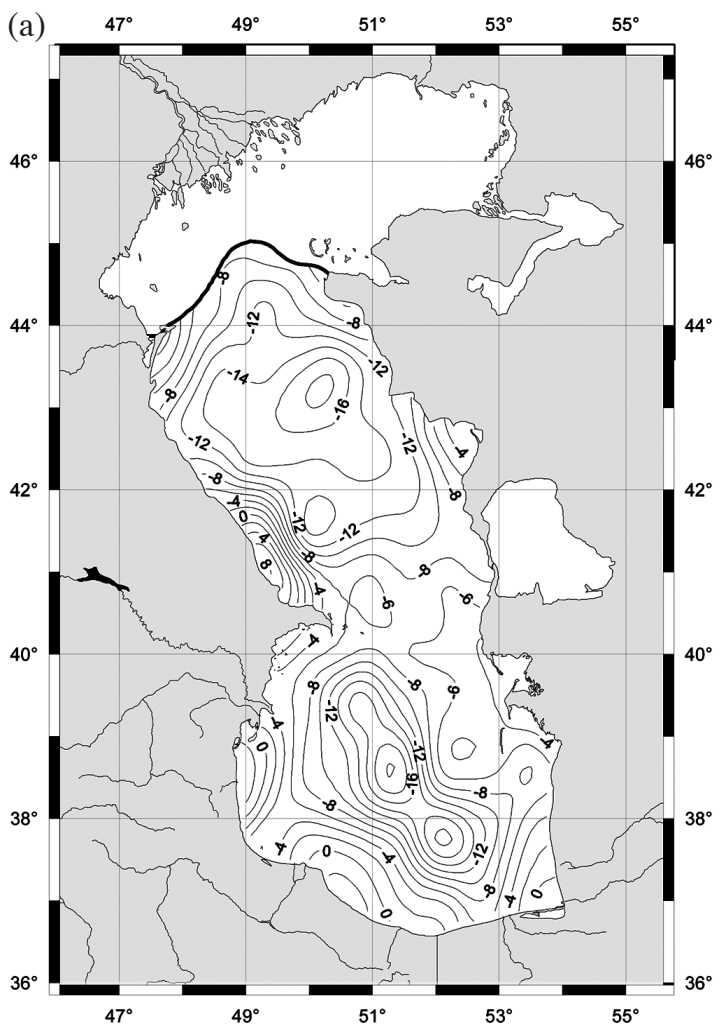

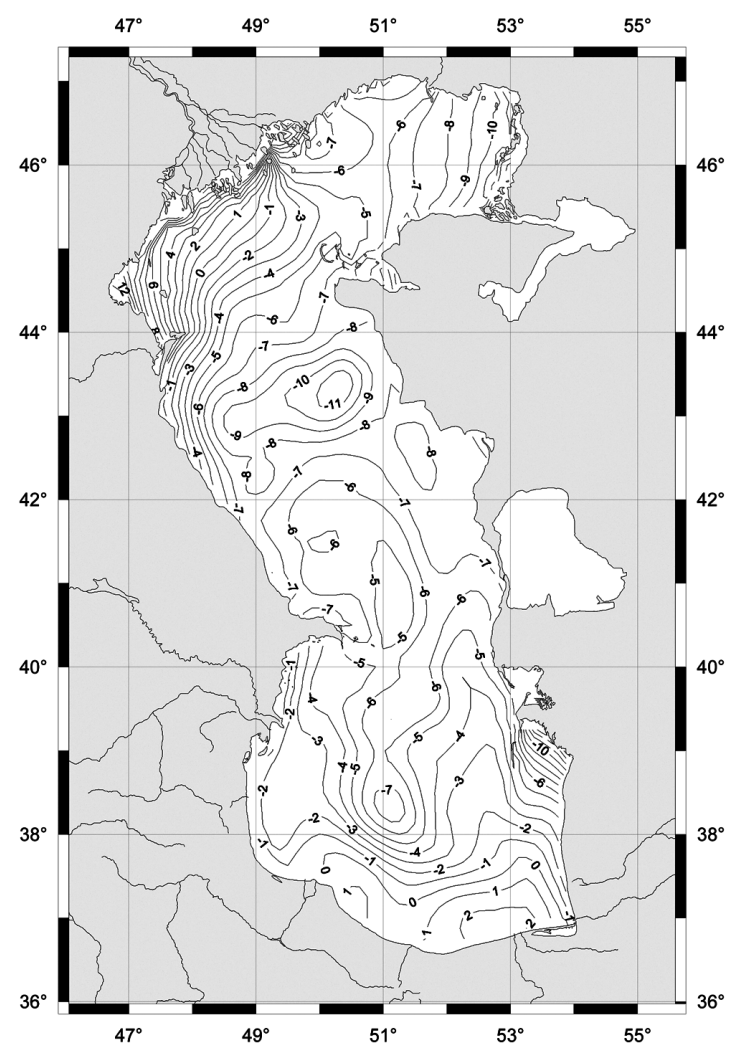

Fig. 9. The climatic or mean dynamic topography $(\mathrm{cm})$ from the numerical hydrodynamic model (Popov 2004).

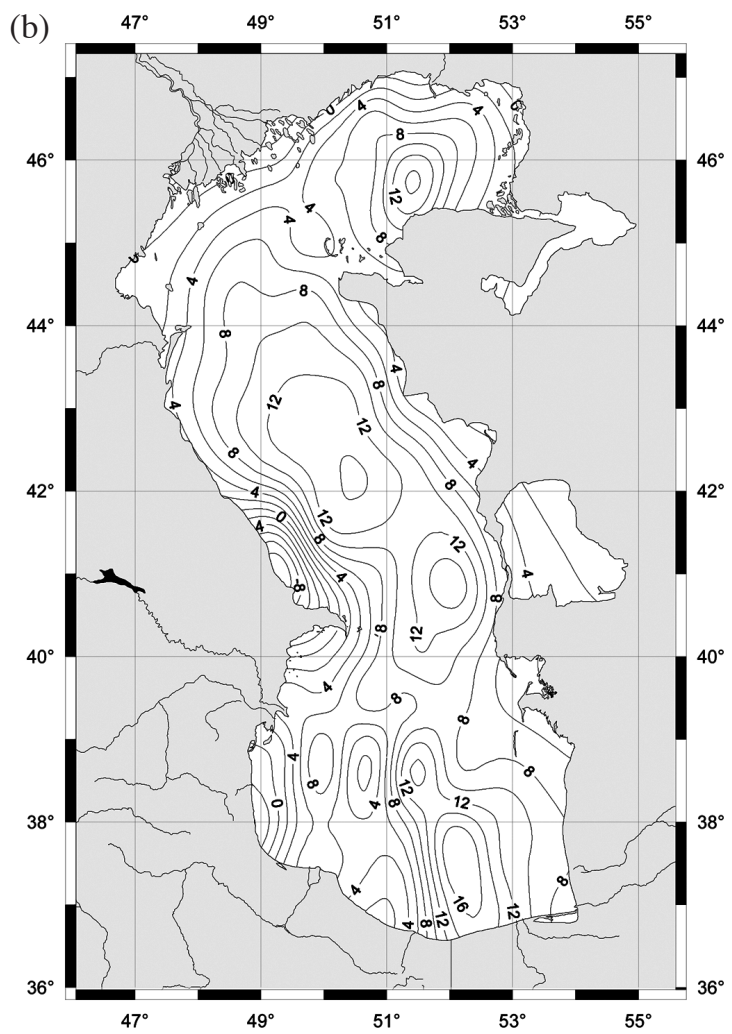

Fig. 10. The seasonal dynamic topography (cm) for January (a) and July (b) for September 1992 - December 2005 on the basis of SA data of the $\mathrm{T} / \mathrm{P}$ and $\mathrm{J} 1$ and results of hydrodynamic simulation on the basis of the HRC model. Bold line shows mean boundary of sea ice in the Northern Caspian. 
(a)

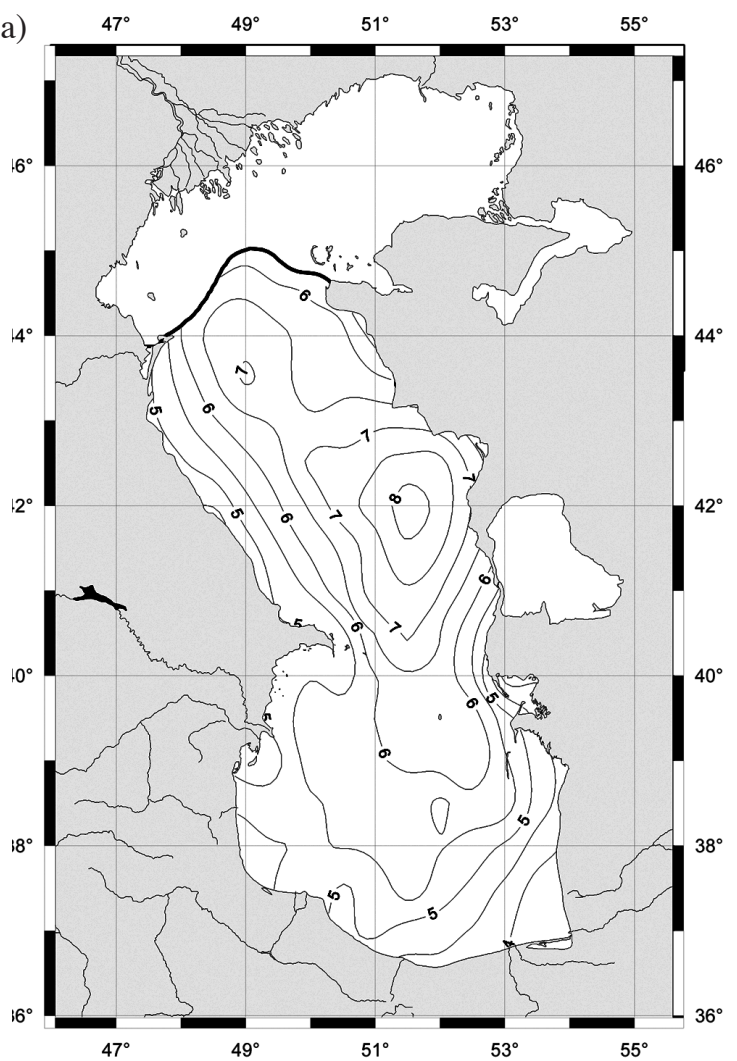

(b)

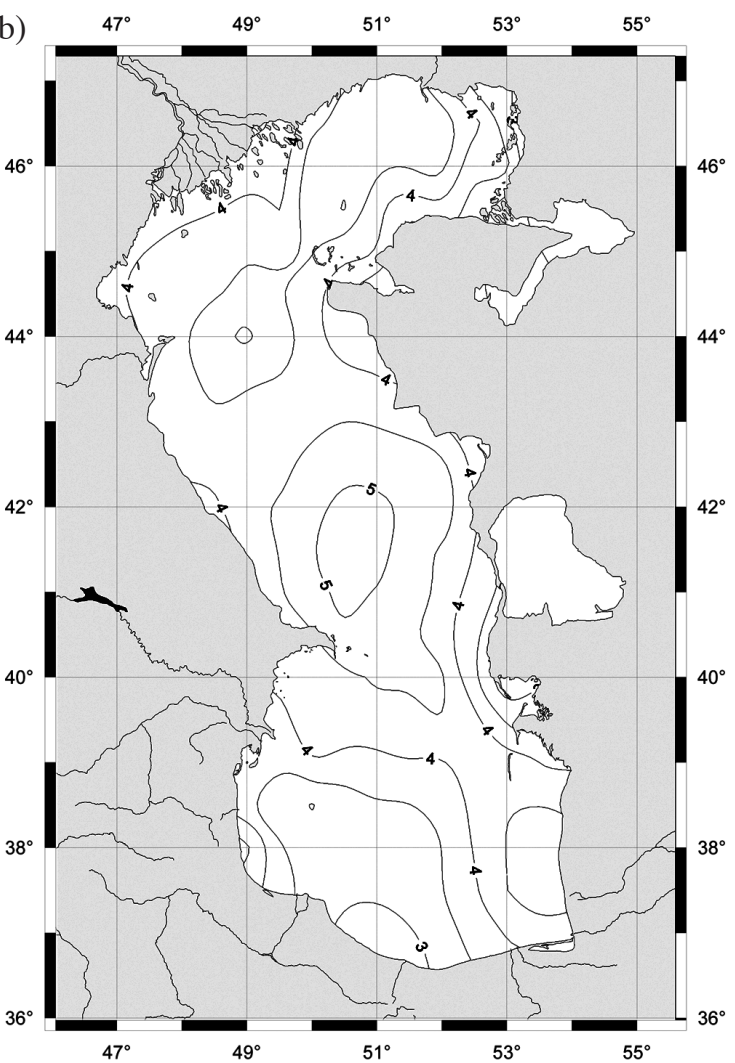

Fig. 11. Fields of wind speed ( $\mathrm{m} \mathrm{s}^{-1}$ ) in January (a) and July (b) for September 1992 - December 2005 on the basis of SA data of the T/P and J1. Bold line shows mean boundary of sea ice in the Northern Caspian.

(a)

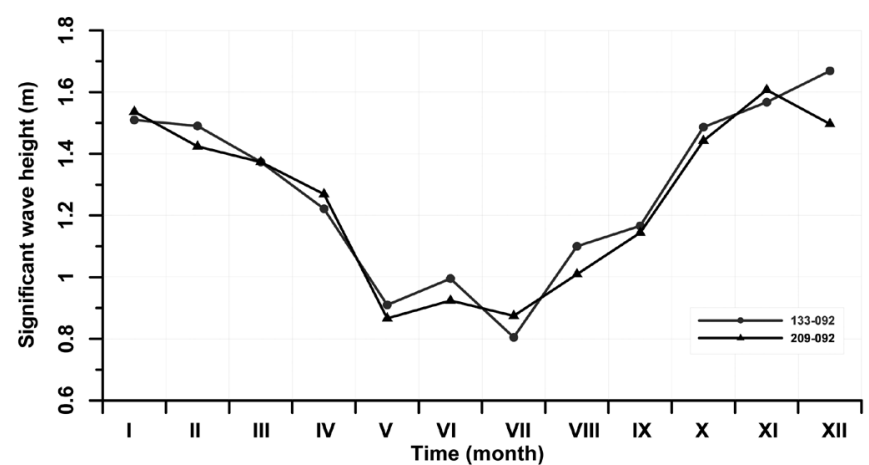

(b)



Fig. 12. Seasonal variability of a significant wave height (m) in (a) the Middle Caspian (at crossover points 133 - 092 and 209 - 092 ) and (b) the Southern Caspian (at crossover points 031 - 092, 031 - 016, and 209 - 016) for September 1992 - December 2005.

\section{THE KARA-BOGAZ-GOL BAY}

In March 1980, in order to restrict losses of Caspian waters and to decelerate the fall of the level of the Caspian Sea, which, in 1977, had been at its lowest for the past 400 500 years (-29 m), the Kara-Bogaz-Gol strait was closed by a nonoverflow sand dam. This resulted in delivery of seawater to the bay being stopped. After the separation of the bay, it rapidly dried off. By the middle of 1984, the bay had become an almost completely dry salt lake. In order to protect and develop this unique salt field on the Caspian Sea, given the appropriate conditions of a rapid sea level rise (Fig. 2), it was decided to rehabilitate the water supply to the KaraBogaz-Gol. In September 1984, Caspian water was fed into the bay at a rate of $1.5-1.6 \mathrm{~km}^{3} \mathrm{yr}^{-1}$. This restricted seawater supply did not result in an active restoration of the hydrological and hydrochemical conditions of the bay. In April 1992 , the area of the bay reached $4600 \mathrm{~km}^{2}$, the absolute level mark was $-33.71 \mathrm{~m}$, and the depths varied from 0.2 to $1.4 \mathrm{~m}$. In June 1992, the dam was destroyed and the natural seawater runoff to the bay resumed. 
The process of refilling the bay and its acquisition of a climatic regime is well traced in the SA data of the T/P and $\mathrm{J} 1$. Fortunately, the start of the T/P mission successfully coincided with the beginning of the filling of the bay (Fig. 13) and the area of the bay is crossed by two tracks of the abovementioned satellites. By the middle of 1996, the rapid filling of the bay with Caspian water (Fig. 13a) had caused a rate of level rise of about $168 \mathrm{~cm} \mathrm{yr}^{-1}$ (Lebedev and Kostianoy 2005). Then, the level rise stopped and its variations started to reflect seasonal changes (Fig. 13b) well correlated with the seasonal level changes of the Caspian Sea. Thus, the rate of level fall (until winter 2001/2002) in both basins comprised approximately $6 \mathrm{~cm} \mathrm{yr}^{-1}$. At present, the level of the bay oscillates near an absolute mark of $-27.5 \mathrm{~m}$.

For accuracy estimation of the offered methodology with Hydroweb and GRLM data was applied. Hydroweb and GRLM data correlate among themselves with a coefficient 0.995 . Data about CSL calculated by the offered methodology correlates with these data as follows: ISADB and Hydroweb at 0.998, ISADB and GRLM at 0.993. This indicates good correlation between results calculated for temporal variation is CSL by SA and SLG data.

\section{THE VOLGA RIVER}

About $80 \%$ of the total river discharge to the Caspian Sea is provided by the Volga River. The mean annual runoff of which is about $240 \mathrm{~km}^{3} \mathrm{yr}^{-1}$. The greatest runoff, equal to $368 \mathrm{~km}^{3} \mathrm{yr}^{-1}$, was recorded in 1926, while the minimum and extremely small values equal to 150 and $163 \mathrm{~km}^{3} \mathrm{yr}^{-1}$ were noted in 1921 and 1973, respectively. Thus, during the past century, the differences in the VRD exceeded $200 \mathrm{~km}^{3} \mathrm{yr}^{-1}$. Up to $25 \%$ of the VRD runoff is supplied to the sea in May - June during the flood periods.

River water level variability was analyzed also based on SSH in crossover points of 235 track with the river-bed (Fig. 14). The obtained results were verified with water discharge rates at the Volgograd hydro-electric power station located far upstream (Fig. 15). The correlation coefficient was about 0.83 for annual values and 0.71 for monthly mean values. The flood low volume in spring 1996 was well tracked in both data types. The negative SSH trend (a)

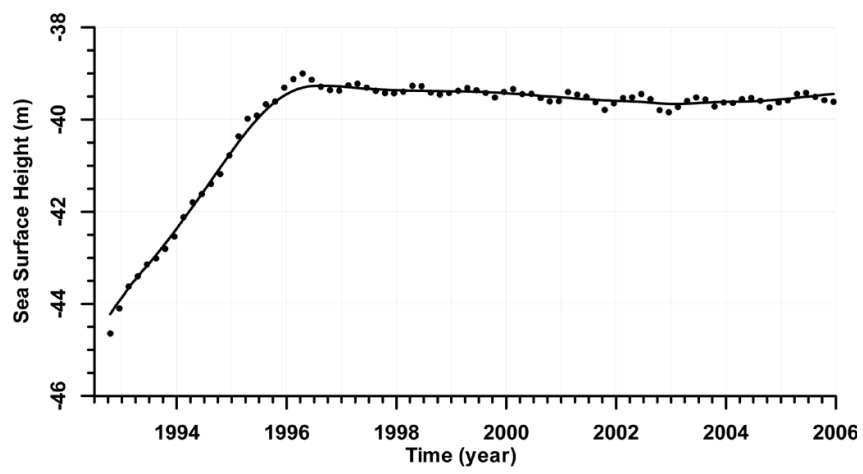

(b)

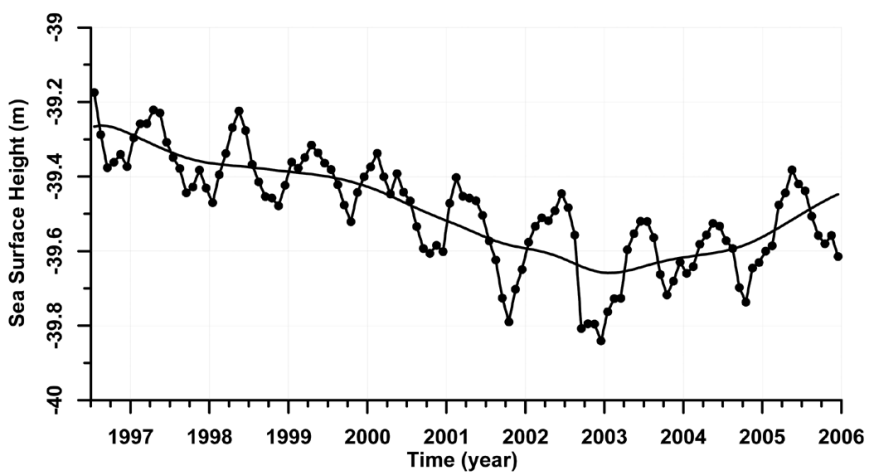

Fig. 13. Interannual and seasonal variability of SSH (m) in the Kara-Bogaz-Gol Bay at crossover point 031 - 168 in (a) September 1992 - December 2005, and (b) July 1996 - December 2005.

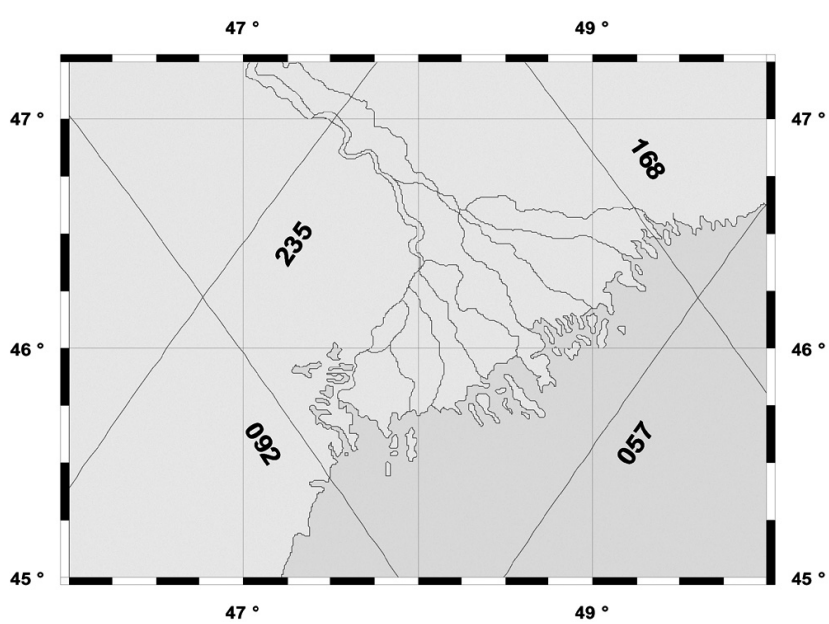

Fig. 14. The Volga River delta and T/P and J1 ground tracks.

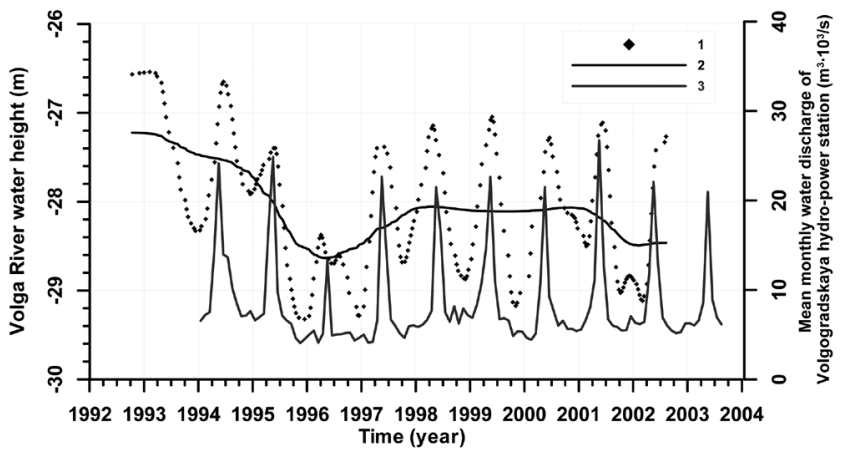

Fig. 15. Variations of (1) the Volga River SSH (m); (2) SSH interannual variability derived from T/P altimetry (January 1992 - December 2003); and (3) mean monthly water discharge at the Volgograd power station. 
of $46.7 \mathrm{~cm} \mathrm{yr}^{-1}$ in 1993 - 1996 corresponds to the decrease in average annual water discharge in the Volgograd power station from 10654 to $5609 \mathrm{~m}^{3} \mathrm{~s}^{-1}$. Close to the track pass there are three hydrological stations on the river; these are at Enotaevka, Seroglazovka and Verkhnee Lebyajye. Satellite SSH correlates with daily measurements at these stations much better at $0.8-0.9$ (Lebedev and Kostianoy 2005).

Acknowledgements This study was supported by the project for "Elaboration of technologies for multi-level regionally adapted ecological and geodynamical monitoring of the Russian seas" of the Federal Program of the Ministry of Education and Science of the Russian Federation "Investigations and elaborations in the priority fields of science and technology", a series of grants of the Russian Foundation for Basic Research (06-05-64871,07-05-00141), by the NATO SfP Project 981063 "Multidisciplinary Analysis of the Caspian Sea Ecosystem" (MACE) and by the INTAS Project “ALTImetry for COastal REgions” (ALTICORE).

\section{REFERENCES}

Arpe, K., L. Bengtsson, G. S. Golitsyn, I. I. Mokhov, V. A. Semenov, and P. V. Sporyshev, 2000: Connection between Caspian Sea level variability and ENSO. Geophys. Res. Lett., 27, 2693-2696, doi: 10.1029/1999GL 002374.

Benada, R. J., 1997: Merged GDR (TOPEX/POSEIDON). Generation B Users Handbook, Version 2.0, Physical Oceanography Distributed Active Archive Center (PODAAC), Jet Propulsion Laboratory, Pasadena, JPL D-11007, $131 \mathrm{pp}$.

Birkett, C. M., 1995: The contribution of TOPEX/ POSEIDON to the global monitoring of climatically sensitive lakes. J. Geophys. Res., 100, 25179-25204, doi: 10.1029/95JC02125.

Cazenave, A., P. Bonnefond, K. Dominh, and P. Schaeffer, 1997: Caspian sea level from TOPEX/ POSEIDON altimetry: Level now falling. Geophys. Res. Lett., 24, 881-884, doi: 10.1029/97GL00809.

Chelton, D. B., J. C. Ries, B. J. Haines, L. L. Fu, and P. S. Callahan, 2001: Satellite altimetry. In: Fu, L. L., and A. Cazanave (Eds.), Satellite Altimetry and Earth Sciences, A handbook of techniques and applications, Academic Press, San Diego, 1-131.

Cretaux, J. F., A. Kouraev, M. Berge-Nguyen, A. Cazenave, and F. Papa, 2006: Satellite altimetry for monitoring lake level changes. In: Vogtmann, H., and N. Dobretsov (Eds.), Transboundary Water Resources: Strategies for Regional Security and Ecological Stability, NATO Science Series: IV: Earth and Environmental Sciences, Springer, Netherlands, 46, 141-146, doi: 10.1007/1-40 20-3082-7_12.

Fenoglio-Marc, L., 2001: Analysis and representation of regional sea level variability from altimetry and atmospheric-oceanic data. Geophys. J. Int., 145, 1-18, doi: 10.1046/j.1365-246x.2001.00284.x.

Fu, L. L., and G. Pihos, 1994: Determining the response of sea level to atmospheric pressure forcing using TOPEX/ POSEIDON data. J. Geophys. Res., 99, 24633-24642, doi: 10.1029/94JC01647.

Ginzburg, A. I., A. G. Kostianoy, and N. A. Sheremet, 2005: Sea surface temperature variability. In: Kostianoy, A. G., and A. N. Kosarev (Eds.), The Caspian Sea Environment, Springer-Verlag, Berlin, Heidelberg, New York, 59-81, doi: 10.1007/698_5_004.

Golitsyn, G. S., and G. N. Panin, 1989: On water balance and the present variations in the Caspian Sea level. Meteorol. Gidrol., 1, 57-64.

Golitsyn, G. S., 1995: The Caspian Sea level as a problem of diagnosis and prognosis of the regional climate change. Atmos. Ocean. Phys., 31, 366-372.

Hernandez, F., and P. Schaeffer, 2000: Altimetric mean sea surfaces and gravity anomaly maps inter-comparisons. AVISO Technical Report, AVI-NT-011-5242-CLS, Toulouse, $48 \mathrm{pp}$.

Hwang, C., M. F. Peng, J. Ning, J. Luo, and C. H. Sui, 2005: Lake level variations in China from TOPEX/Poseidon altimetry: Data quality assessment and links to precipitation and ENSO. Geophy. J. Int., 161, 1-11, doi: 10.1111/j.1365-246X.2005.02518.x.

Kistler, R., E. Kalnay, W. Collins, S. Saha, G. White, J. Woollen, M. Chelliah, W. Ebisuzaki, M. Kanamitsu, V. Kousky, H. van den Dool, R. Jenne, and M. Fiorino, 2001: The NCEP-NCAR 50-year reanalysis: Monthly means CD-ROM and documentation. Bull. Amer. Meteorol. Soc., 82, 247-267.

Koblinsky, C. J., R. Ray, B. D. Becley, Y. M. Wang, L. Tsaoussi, A. Brenner, and R. Williamson, 1999a: NASA Ocean Altimeter Pathfinder Project. NASA Goddard Space Flight Center - Report 1: Data Processing Handbook, NASA/TM-1998-208605, 55 pp.

Koblinsky, C. J., R. Ray, B. D. Becley, Y. M. Wang, L. Tsaoussi, A. Brenner, and R. Williamson, 1999b: NASA Ocean Altimeter Pathfinder Project. NASA Goddard Space Flight Center - Report 2: Data Set Validation, NASA/TM-1999-209230, 56 pp.

Kosarev, A. N., and E. A. Yablonskaya, 1994: The Caspian Sea, SPB Academic Publishing, The Hague, 259 pp.

Kostianoy, A. G., P. O. Zavialov, and S. A. Lebedev, 2004: What do we know about dead, dying and endangered lakes and seas? In: Nihoul, J. C. J, P. O. Zavialov, and Ph. P. Micklin (Eds.), Dying and Dead Seas, NATO ARW/ASI Series, Kluwer Acad. Publ., Dordrecht, $1-48$.

Kouraev, A. V., F. Papa, N. M. Mognard, P. I. Buharizin, A. Cazenave, J. F. Cretaux, J. Dozortseva, and F. Remy, 2004: Sea ice cover in the Caspian and Aral Seas from 
historical and satellite data. J. Mar. Syst., 47, 89-100, doi: 10.1016/j.jmarsys.2003.12.011.

Larnicol, G., P. Y. Le Traon, N. Ayoub, and P. De Mey, 1995: Mean sea level and surface circulation variability of the Mediterranean Sea from 2 years of TOPEX/ POSEIDON altimetry. J. Geophys. Res., 100, 2516325177, doi: 10.1029/95JC01961.

Lebedev, S. A., O. I. Zilberstein, S. K. Popov, and O. V. Tikhonova, 2003: Analysis of temporal sea level variation in the Barents and the White Seas from altimetry, tide gauges and hydrodynamic simulation. In: Hwang, C., C. K. Shum, and J. C. Li (Eds.), International Workshop on Satellite Altimetry, International Association of Geodesy Symposia, 126, Springer-Verlag, Berlin, Heidelberg, 243-250.

Lebedev, S. A., and A. G. Kostianoy, 2005: Satellite Altimetry of the Caspian Sea. Moscow Sea. (in Russian)

Medvedev, P. P., S. A. Lebedev, and Y. S. Tyupkin, 1997: An integrated data base of altimetric satellite for fundamental geosciences research. In: Proc. First EastEuropean Symp. Adv. in Data Bases and Information Systems (ADBIS'97) St.-Petersburg, Russia, September 2 - 5, 1997, St. Petersburg, St. Petersburg Univ., 2, 95-96.

Mercier, F., A. Cazenave, and C. Maheu, 2002: Interannual lake level fluctuations in Africa (1993 - 1999) from Topex-Poseidon: Connections with ocean-atmosphere interactions over the Indian Ocean. Global Planet. Change, 32, 141-163, doi: 10.1016/S0921-8181(01) 00139-4.

Mikhailov, V. N., 1998: The Volga River-Mouth area: Hydrological-morphological processes, regime of contaminants and influence of the Caspian Sea level changes. Geos. Press, Moscow, Russia, 278 pp. (in Russian)

Morris, G. S., and S. K. Gill, 1994a: Variation of Great Lakes water levels derived from GEOSAT altimetry. Water Resour. Res., 30, 1009-1017, doi: 10.1029/94WR 00064.

Morris, G. S., and S. K. Gill, 1994b: Evaluation of the TOPEX/POSEIDON altimeter system over the Great Lakes. J. Geophys. Res., 99, 24527-24540. doi: 10.1029 194JC01642.

Nerem, R. S., and G. T. Mitchum, 2001: Sea Level change. In: Fu, L. L., and A. Cazenave (Eds.), Satellite Altimetry and Earth Sciences, A Handbook of Techniques and Applications, Academic Press, San Diego, 329-350.

Nezlin, N. P., 2005: Patterns of Seasonal and interannual variability of remotely sensed chlorophyll. In: Kostianoy, A. G., and A. N. Kosarev (Eds.), The Caspian Sea Environment, Springer-Verlag, Berlin, Heidelberg, New York, 143-157, doi: 10.1007/698_5_007.

Panin, G. N., A. V. Dzuyba, and A. G. Osipov, 1991: On possible causes of changes in the evaporation in the Caspian Sea region during past decades. Water Re- sour., 18, 5-16.

Panin, G. N., and A. V. Dzuyba, 2003: Current variations in the wind speed vector and the rate of evaporation from the Caspian Sea surface. Water Resour., 30, 177184, doi: 10.1023/A:1022966021168. doi: 10.1023/A: 1022966021168.

Picot, N., K. Case, S. Desai, and P. Vincent, 2006: AVISO and PODAAC User Handbook. IGDR and GDR Jason Products, SMM-MU-M5-OP-13184-CN(AVISO), JPL D-21352 (PODAAC), Edition 3., 112 pp.

Popov, S. K., 2004: Simulation of climatic thermohaline circulation of the Caspian Sea. Meteorol. Hydrol., 5, 76-84. (in Russian)

Rapp, R. H., 1998: Past and future developments in geopotential modelling. In: Forsberg, R., M. Feissel, and R. Dietrich (Eds.), Geodesy on the Move, Gravity, Geoid, Geodynamics and Antarctica, IAG Symposia, 119, Springer, Berlin, 58-78.

Rodionov, S. N., 1994: Global and regional climate interaction: The caspian sea experience. Water Sci. Technol. Libr., 11, 241 pp.

Scherneck, H. G., J. M. Johansson, M. Vermeer, J. L. Davis, G. A. Milne, and J. X. Mitrovica, 2001: BIFROST project: 3-D crustal deformation rates derived from GPS confirm postglacial rebound in Fennoscandia. Earth Planets Space, 53, 703-708.

Tapley, B. D., and M. C. Kim, 2001: Applications to geodesy. In: Fu, L. L., and A. Cazenave (Eds.), Satellite Altimetry and Earth Sciences, A Handbook of Techniques and Applications, Academic Press. San Diego, 371-406.

The Caspian Sea Environment, 2005: In: Kostianoy, A. G., and A. N. Kosarev (Eds.), Springer-Verlag, Berlin, Heidelberg, New York, 271 pp.

Vasiliev, A. S., V. B. Lapshin, Yu. V. Lupachev, P. P. Medvedev, and S. V. Pobedonostsev, 2002: Research of the Caspian Sea level by satellite altimetric measurements. In: Investigations of the Oceans and Seas, Proceedings of State Oceanographic Institute, Hydrometeoizdat, St. Petersburg, 208, 277-292. (in Russian)

Verbitskaya, O. A., O. I. Zilberstein, S. K. Popov, and A. L. Lobov, 2003: Operational model of short-term sea level forecast in the Caspian Sea. In: Proceedings of the MEDCOAST International Conference, Ravenna, Italy, 2003. P. 2179-2187.

Voropayev, G. V., 1997: The problem of the Caspian Sea level forecast and its control for the purpose of management optimization. In: Glantz, M. H., and I. S. Zonn (Eds.), Scientific, Environmental, and Political Issues in the Circum-Caspian Region, Cambridge University Press, Cambridge, UK, 105-118.

Wang, Y. M., 2000: The satellite altimeter data derived Mean Sea Surface GSFC98. Geophys. Res. Lett., 27, 701-704, doi: 10.1029/1999GL002375. 